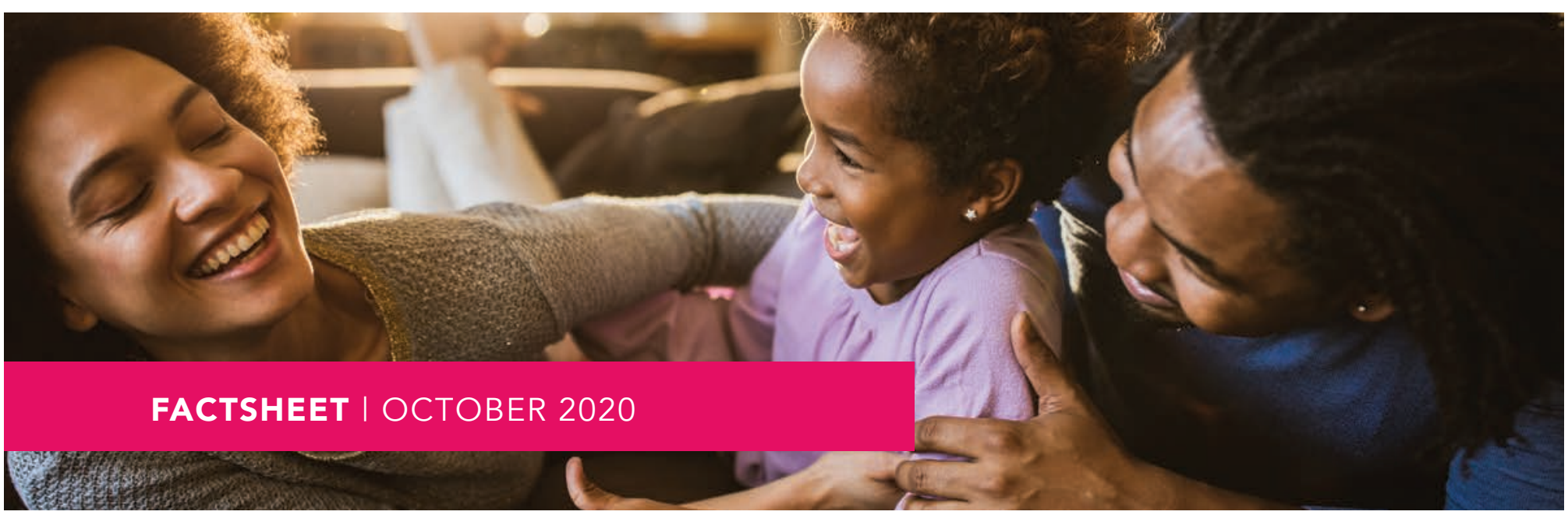

\title{
How the Child Welfare System Works
}

The child welfare system is not a single entity. Many organizations in each community work together to strengthen families and keep children safe. Public agencies, such as departments of social services or child and family services, often contract and collaborate with private child welfare agencies and community-based organizations to provide services to families, such as in-home family preservation services, foster care, residential treatment, mental health care, substance use treatment, parenting skills classes, domestic violence services, employment assistance, and financial or housing assistance.

Child welfare systems are complex, and their specific procedures vary widely by State. The purpose of this factsheet is to give a brief overview of the purposes and functions of child welfare from a national perspective.

\section{WHAT'S INSIDE}

What is the child welfare system?

What happens when possible abuse or neglect is reported?

What happens after a report is screened in?

What happens in substantiated cases?

\section{Summary}

References

Appendix: The child welfare system

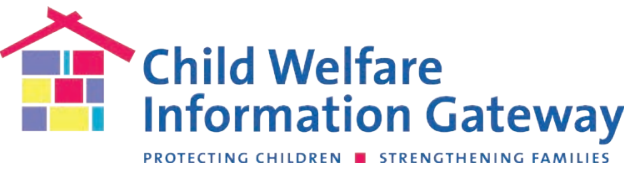




\section{WHAT IS THE CHILD WELFARE SYSTEM?}

The child welfare system is a group of services designed to promote the well-being of children by ensuring safety, achieving permanency, and strengthening families. While the primary responsibility for child welfare services rests with the States, the Federal Government supports States through program funding and legislative initiatives.

The Children's Bureau within the U.S. Department of Health and Human Services' Administration for Children and Families holds the primary responsibility for implementing Federal child and family legislation. The Children's Bureau works with State and local agencies to develop programs that focus on preventing child abuse and neglect by strengthening families, protecting children from further maltreatment, reuniting children safely with their families, and finding permanent families for children who cannot safely return home. For more information on child welfare legislation and policy, see Child Welfare Information Gateway's Major Federal Legislation Concerned With Child Protection, Child Welfare, and Adoption. For more on how child welfare programs are funded, see Information Gateway's Funding web section.

Most families first become involved with the child welfare system because of a report of suspected child abuse or neglect, which is also referred to as "child maltreatment." Child maltreatment is defined by CAPTA as serious harm (e.g., physical abuse, sexual abuse, emotional abuse, neglect) caused to children by parents or primary caregivers, such as extended family members or babysitters. Child

\section{The Child Abuse Prevention and Treatment Act}

The Child Abuse Prevention and Treatment Act (CAPTA), originally passed in 1974, brought national attention to the need to protect vulnerable children in the United States. CAPTA provides Federal funding to States in support of the prevention, assessment, investigation, and prosecution of child abuse and neglect as well as grants to public agencies and nonprofit organizations for demonstration programs and projects. Since it was signed into law, CAPTA has been amended several times, most recently by the CAPTA Reauthorization Act of 2010 (P.L. 111-320). For more information, see Information Gateway's About CAPTA: A Legislative History.

maltreatment also can include harm that a caregiver allows to happen to a child or does not prevent from happening.

Each State has its own laws that define abuse and neglect, the reporting obligations of individuals, and the required State and local child protective services (CPS) agency interventions. In general, child welfare agencies do not intervene in cases of harm to children caused by acquaintances or strangers. These cases are generally the responsibility of law enforcement. (In those cases, criminal charges may be filed in court against the perpetrators of child maltreatment.) Some States authorize CPS 
agencies to respond to all reports of alleged child maltreatment, while others authorize law enforcement to respond to certain types of maltreatment, such as sexual or physical abuse. To learn more about child maltreatment and State-by-State information about civil laws related to child abuse and neglect, visit Information Gateway's What Is Child Abuse and Neglect? Recognizing the Signs and Symptoms, Definitions of Child Abuse and Neglect, and the State Statutes database. For data regarding child maltreatment as well as outcomes within the child welfare system, refer to the Children's Bureau's Statistics \& Research web section.

Child welfare systems typically take the following actions:

- Investigate reports (receive and investigate reports of possible child abuse and neglect)

- Support families (provide prevention services to families that need assistance protecting and caring for their children to prevent entry into foster care)

- Provide temporary safe shelter (arrange for children to live with kin or foster families when they are not safe at home)

\section{- Seek to return children to their families} when safety has improved or find other permanent arrangements (arrange for reunification, adoption, or other permanent family connections for children leaving foster care)

\section{WHAT HAPPENS WHEN POSSIBLE ABUSE OR NEGLECT IS REPORTED?}

Any concerned person can report suspicions of child abuse or neglect, and reports may be made anonymously. Most reports are made by people called "mandatory reporters," who are individuals required by State law to report suspicions of child abuse and neglect. These reports are generally received by CPS workers and are either screened in or screened out. A report is screened in when there is sufficient information to suggest an investigation is warranted. A report may be screened out if there is not enough information on which to follow up on or if the situation reported does not meet the State's legal definition of abuse or neglect. In these instances, the CPS worker may refer the person reporting the incident to other community services or law enforcement for additional help.

For additional information about the child welfare system, refer to the following Information Gateway resources:

- Making and Screening Reports of Child Abuse and Neglect

- Mandatory Reporters of Child Abuse and Neglect

- Responding to Child Abuse \& Neglect [webpage]

The flowchart at the end of this factsheet provides an overview of the process described in the following sections. 


\section{WHAT HAPPENS AFTER A REPORT IS SCREENED IN?}

CPS caseworkers respond within a few hours to a few days after a report is entered depending on the type of maltreatment alleged, the potential severity of the situation, and requirements under State law. They may speak with the parents and other people in contact with the child, such as doctors, teachers, or child-care providers. They also may speak with the child, alone or in the presence of caregivers, depending on the child's age and level of risk. Children who are believed to be in immediate danger of continued maltreatment may be moved to a shelter, a foster home, or a relative's home during the investigation and while court proceedings are pending. The caseworker also engages the family to assess their strengths and needs and initiate connections to community resources and services.

At the end of the investigation, CPS caseworkers typically make one of two findings-unsubstantiated (unfounded) or substantiated (founded). These terms vary from State to State. Typically, a finding of unsubstantiated means there is insufficient evidence for the caseworker to conclude that the child was abused or neglected or that what happened does not meet the legal definition of child abuse or neglect. A finding of substantiated maltreatment typically means that an incident of child abuse or neglect, as defined by State law, is believed to have occurred. Some States have additional categories, such as "unable to determine," that suggest there is not enough evidence to either confirm or refute that abuse or neglect occurred.

if the agency determines that the authority of the juvenile court is necessary to keep a child safe, it will initiate a court action, such as a child protection or dependency proceeding. To protect the child, the court can issue temporary orders placing the child in shelter care during the investigation, ordering services, or ordering certain individuals to have no contact with the child. Later, at an adjudicatory hearing, the court hears evidence and decides whether maltreatment occurred and whether the child should be under the continuing jurisdiction of the court For additional information about the legal process, refer to Information Gateway's Understanding Child Welfare and the Courts.

Some jurisdictions employ an alternative, or differential, response system. In these jurisdictions, when the risk to the child is considered low, the CPS caseworker-rather than investigating the occurrence of abuse or neglect-focuses on assessing family strengths, resources, and difficulties and on identifying supports and services needed. To learn more about differential response, read Information Gateway's Differential Response: A Primer for Child Welfare Professionals. 


\section{Neglect}

Nearly three-quarters of all child maltreatment cases are related to some form of neglect (Children's Bureau, 2020), which may be the result of a family's need for financial and related social supports. See the following Information Gateway resources to learn more about neglect and how to support families:

- Identification of Neglect [webpage]

- Family Support Policy and Program Support Approaches [webpage]

- Acts of Omission: An Overview of Child Neglect

\section{WHAT HAPPENS IN SUBSTANTIATED CASES?}

If a report of abuse or neglect is substantiated, the next steps for the child and parent depend on State or local policy, the severity of the maltreatment, an assessment of the child's immediate safety, the perceived risk of continued or future maltreatment, the services available to address the family's needs, and whether the maltreatment prompted the child's removal from the home and/or a protective court action. When a report is substantiated as a result of a court hearing, the court may enter a disposition ordering a parent to comply with services necessary to alleviate the abuse or neglect. Orders can also contain provisions regarding visitation requirements between the parent and the child, agency obligations to provide the parent with services, and services needed by the child.
Decisions about services and other next steps may be made by the CPS worker or the courts based on the following categories of perceived risk for future maltreatment:

- Little or no risk. The family's case may be closed with no services if a determination is made that the maltreatment was a one-time incident, the child is considered to now be safe, and there is little or no risk of future incidents. Any services the family needs will be provided through community-based resources and service systems-not the child welfare agency.

- Low to moderate risk. Referrals may be made to community-based or voluntary in-home child welfare services if the CPS worker believes the family would benefit from these services and the child's present and future safety would be enhanced. (This may happen even when no abuse or neglect is found if the family needs and is willing to participate in services.) Local family resource centers or other organizations can provide community-based services related to parent skill training, child care, housing needs, job training, substance use and mental health counseling, or respite and crisis care services.

- Moderate to high risk. The family may be offered voluntary in-home services to address safety concerns and help reduce the risks. If these are refused, the agency may seek intervention by the juvenile dependency court. The court may in turn require the family to cooperate with inhome services if it is believed the child can remain safely at home while the family addresses the issues contributing to the perceived risk of future maltreatment. If the child has already been seriously harmed, is 
considered to be at high risk of serious harm, or the child's safety is threatened, the court may order the child's removal from the home or affirm the agency's prior removal of the child. The child may be placed with a relative or in foster care.

\section{Central Registries for Child Maltreatment}

Whether or not criminal charges are filed, the name of the person committing the abuse or neglect may be placed in a State child maltreatment registry if the abuse or neglect is confirmed. A registry is a central database that collects information about maltreated children and individuals who are found to have abused or neglected their children. These registries are usually confidential and used for internal child protective purposes only. Information about perpetrators, however, may be used in background checks for certain professions that involve working with children to help prevent children from coming into contact with individuals who may mistreat them.

For more information about these registries, see Information Gateway's Establishment and Maintenance of Central Registries for Child Abuse or Neglect Reports.
Depending on the severity of the case and other factors, children may be removed from their homes and placed in foster care. Most children in foster care are placed with relatives or foster families, but some may be placed in a group or residential setting. While in foster care, the child attends school and receives medical care and other services as needed. The child's family also receives services to support their efforts to reduce the risk of future maltreatment and to help them reunite with their child. Visits between parents and their children and between siblings are established as appropriate or according to the case plan.

Every child in foster care should have a permanency plan. Federal law requires the court to hold a permanency hearing, during which a child's permanency plan is developed. This should take place within 12 months of a child entering foster care and every 12 months thereafter. The courts may review each case more frequently to ensure the agency is actively pursuing permanency for the child. (See Information Gateway's Legal and Court Issues in Permanency web section for more information.) The child's family typically participates in developing the permanency plan for the child, as well as their own service plan. Family reunification, except in unusual and extreme circumstances, is the permanency plan for most children. In some cases, when prospects for reunification appear less likely, a concurrent permanency plan may be developed. If the efforts toward reunification are not successful, the plan may be changed to another permanent 
arrangement, such as adoption or transfer of custody to a relative. For more information on reunification and concurrent planning, see Information Gateway's Supporting Successful Reunifications, Concurrent Planning for Timely Permanence, and Concurrent Planning for Permanency for Children.

In addition to receiving support in developing permanent legal and relational connections to family and other important people in their lives, older youth in foster care should receive transitional or independent living services to help prepare them for self-sufficiency in the event they leave foster care without a permanent family. Information Gateway's Achieving \& Maintaining Permanency and Permanency for Youth webpages offer related resources. Depending on State law, youth may age out of foster care somewhere between the ages of 18 and 21.

\section{SUMMARY}

The goal of child welfare is to promote the well-being, permanency, and safety of children and families by helping families care for their children successfully or, when that is not possible, helping children find permanency with kin or adoptive families. Among children who enter foster care, most will return safely to the care of their own families or go to live with relatives or an adoptive family.
For more detailed information about the child welfare system, please refer to the resources listed below. For more information about the child welfare system in your State or local jurisdiction, contact your local public child welfare agency.

\section{REFERENCES}

Children's Bureau. (2020). Child maltreatment 2018. U.S. Department of Health and Human Services, Administration for Children and Families. https://www. acf.hhs.gov/cb/resource/childmaltreatment-2018

\section{SUGGESTED CITATION:}

Child Welfare Information Gateway. (2020). How the child welfare system works. U.S. Department of Health and Human Services, Administration for Children and Families, Children's Bureau. https://www.childwelfare. gov/pubs/factsheets/cpswork/

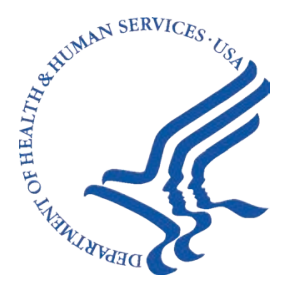

U.S. Department of Health and Human Services

Administration for Children and Families

Administration on Children, Youth and Families

Children's Bureau
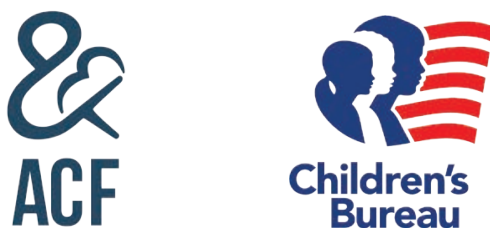

This material may be freely reproduced and distributed. However, when doing so, please credit Child Welfare Information Gateway. This publication is available online at https://www.childwelfare.gov/pubs/factsheets/cpswork/. 


\section{Child abuse or neglect suspected.}

\section{Welfare}

Professional or community member reports suspected maltreatment to CPS. Worker screens report.

\section{System}

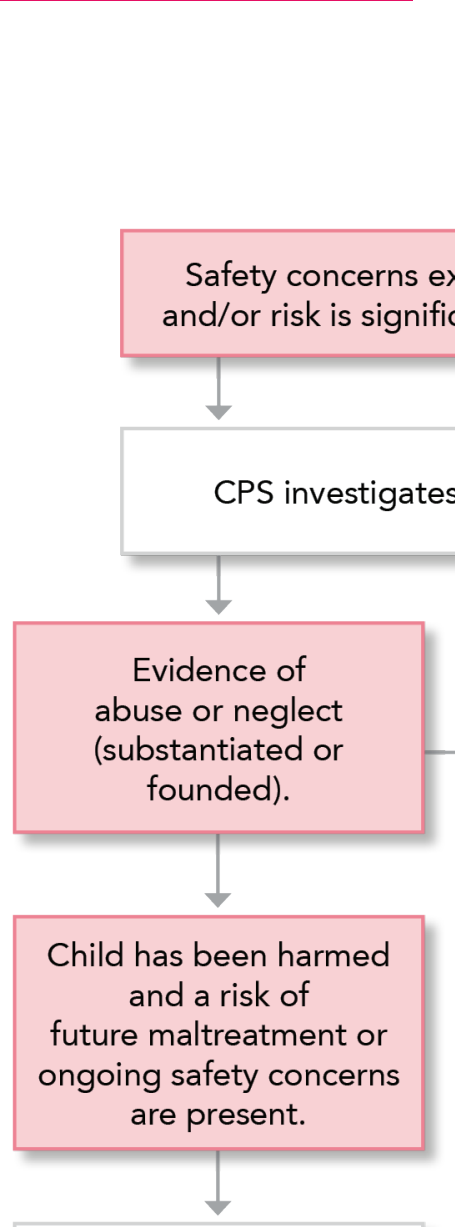

Report is screened in.

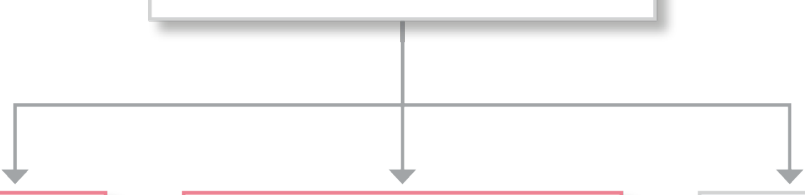

the State's definition of maltreatment, or too little information is supplied. Report is screened out. Caller may be referred elsewhere.

There are no safety

Safety concerns and risk are moderate. concerns and risk is low.

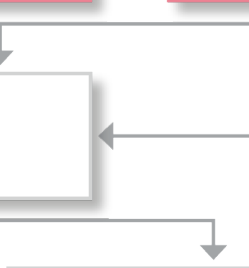

Insufficient evidence of abuse or neglect (unsubstantiated or unfounded).

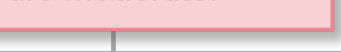

|r

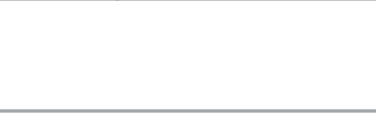

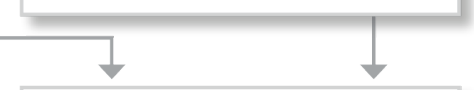

CPS may conduct a
family assessment.

CPS may conduct a
family assessment.

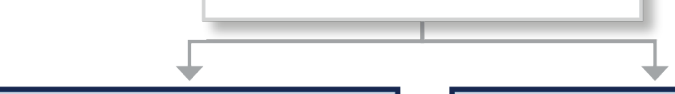

Child welfare or community-based services may be offered to address family needs.
No services are found to be appropriate. Family may be referred elsewhere.

\section{Court petition} may be filed.
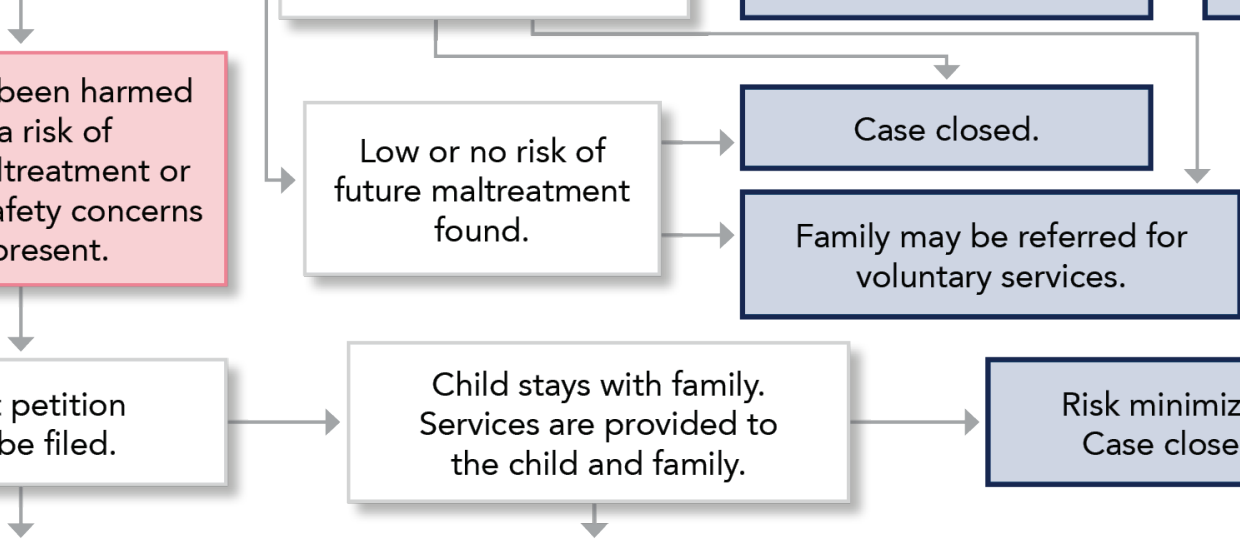

Child stays with family. Services are provided to the child and family.
Risk minimized. Case closed.

Child is placed in out-of-home care, and services are provided to the child and family.$$
\checkmark
$$

Child is reunified with the family.
Custody granted to a relative.
Parental rights are terminated, and case proceeds to adoption or permanent legal guardianship.
Older youth leave care for independent living, ideally with permanent family connections. 